\begin{tabular}{ll}
\hline & $\begin{array}{l}\text { Kastamonu Eğitim Dergisi } \\
\text { Kastamonu Education Journal }\end{array}$ \\
$\begin{array}{l}\text { Ocak 2019 Cilt:27 Sayı:2 } \\
\text { kefdergi.kastamonu.edu.tr }\end{array}$ & Başuru Tarihi/Received: 29.01 .2018 \\
& Kabul Tarihi/Accepted: 18.05 .2018 \\
Dol: $10.24106 /$ kefdergi.2612
\end{tabular}

\title{
Yetişkin Motivasyon Ölçeği: Bir Ölçek Geliştirme Çalışması
}

\section{Adult Motivation Scale: A Scale Development Study}

\section{Öz}

\author{
Öznur TULUNAY ATEŞ ${ }^{1}$, Neslin IHTTIYAROĞLU²
}

Çalışmanın amacı, yetişkinlerin motivasyon düzey ve yönelimlerini belirlemek üzere bir ölçek geliştirmektir. Yapılan açımlayıcı ve doğrulayıcı faktör analizi sonucu iki faktörden ve 21 maddeden oluşan ölçek elde edilmiştir. Ölçeğin iç geçerliği, \%27'lik üst ve alt gruplar 'bağımsız gruplarda t testi' ile değerlendirilmiş ve farkın istatistiksel olarak anlamlı olduğu sonucuna ulaşılmıştr. Ölçeğin güvenilirliği için Cronbach alfa güvenilirliği yöntemi kullanılmıştır. Analizlerde ölçeğin, Cronbach Alpha güvenirlik katsayısı 0,94 olduğu ve iki bileşenin birlikte toplam varyansın \%47,95'ini açıkladığı görülmüştür. Doğrulayıcı faktör analizi çalışmaları sonucuna göre, önerilen modele ilişkin uyum indekslerinden GFI (0.85), CFI (0.96), NFI (0.91), RMSEA (0.06), CFI (0.96), AGFI (0.82), SRMR (0.06) olarak hesaplanmıştı. Elde edilen değerler modelin gözlenen yapıya uygun olduğunu göstermektedir. Yapılan geçerlik ve güvenilirlik analizleri, ölçeğin en az ilkokul mezunu olan 20-60 yaşları arasındaki kadın ve erkek bireylere uygulanabileceğini göstermiştir.

Anahtar Kelimeler: motivasyon, içsel motivasyon, dışsal motivasyon, yetişkin motivasyon, ölçek geliştirme.

\section{Abstract}

The purpose of this study is to develop a scale to determine adults' motivation levels and their tendencies. As a result of exploratory and confirmatory factor analyzes, the scale two major factors and 21 items was obtained. $27 \%$ top and bottom groups were evaluated with 'independent group $t$ test' and it was concluded that the difference was statistically significant. In the analysis for the scale cronbach's Alpha reliability coefficient is 0,94 and, two components all together have been shown explained $47,95 \%$ of the total variance. Cronbah's Alpha reliability coefficient of the scale was found to be 0,94 . Two components all together explained $47,95 \%$ of the variance. According to confirmatory factor analysis' results, GFI (0.85), CFI (0.96), NFI (0.91), RMSEA (0.06), CFI (0.96), AGFI (0.82) as goodness fit indices were calculated. The findings indicated the model was fit to observed structure. Validity and reliability analyses applied have revealed that the scale can be applied to female and male individuals who are at least primary school graduates and between the ages of 20-60.

Keywords: motivation, intrinsic motivation, extrinsic motivation, adult motivation, scale development.

1. Mehmet Akif Ersoy Üniversitesi, Eğitim Fakültesi, Burdur, Türkiye; https://orcid. org/0000-0003-1784-7227.

2. Kırıkkale Üniversitesi, Eğitim Fakültesi, Kırıkkale, Türkiye; https://orcid.org/0000-0002-3872-0922.

Atff / Citation: Tulunay Ateş, A., \& Ihtiyaroğlu, N. (2019). Yetişkin motivasyon ölçeği: bir ölçek geliştirme çalışması. Kastamonu Education Journal, 27(2), 611-620. doi:10.24106/kefdergi.2612 


\section{Extended Summary}

Introduction: Each factor related to human deserves importance for society and organization, since human is building block of society and the most important source of organization. Understanding the importance of human has led to increase the number of researches on this issue. Researchers conducted show the effect of motivation on feelings, thoughts and behaviors. During the adulthood period, it can be said that motivation plays a significant role in increasing an individual's academic achievement and professional performance. Therefore, the aim of this study is to develop "adult motivation scale". In terms of motivation in the study, the difference between intrinsic and extrinsic motivation included in Self-Determination theory is followed.

Methodology: This study, conducted in screening model, was carried on participants using the random sampling method from Bartin province in 2017. Number of participants was 23 in the preliminary practice, 345 for exploratory factor analysis and 173 for confirmatory factor analysis. The study group consists of 541adult in total who are at least primary school graduate and aged between 20-60, including 364 students from the faculty of engineering, 143 teachers, 34 employees from fields of health and law.

In the process of developing scale in the study, the literature was scanned, similar scales developed by researchers were examined and an item pool consisting of 35 questions was formed. Item count was arranged in accordance with expert opinions and reduced to 33. Then, as a result of the preliminary application conducted with 23 college students, 3 items that were not understood were removed, and 30-item scale was established. In the scale, five-point Likert-type measuring form was used including "I strongly disagree", "I disagree", "I moderately agree", "I agree" and "I strongly agree".

Before data analysis, extreme, missing and incorrect values were examined, and forms belonging to 7 people which were considered to affect normality of data set were removed from data. In the study, Kaiser-Meyer-Olkin (KMO) and Bartlett tests were used to examine whether data was suitable for factor analysis. Exploratory factor analysis (EFA) was used in structure validity of the scale, and confirmatory factor analysis (CFA) was applied to test accuracy of factor structure obtained as a result of previous analysis. Expert opinion was used for scope validity. In reliability study, internal consistency (Cronbach's Alpha) values were calculated. In addition, item total score correlation and $27 \%$ lower-upper group compareson were applied. CFA was used to analyse model fit of the scale obtained with EFA. Multiple fit indices (X2, sd, X2/sd, RMSEA, CFI, GFI, AGFI, SRMR, NFI) were used in CFA.

Findings and Discussion: As result of the analyses conducted, Kaiser-Meyer-Olkin value of the scale was found as 0.94 , and Bartlett test result was found as 4982.53 . Analysing item total correlations of the scale before factor analysis, it was observed that item total correlation coefficients ranged between 0.42 and 0.72 , $t$-values ranged between 8.04 and 15.02. As a result of evaluations made, no items were removed from the scale. Acceptance point for factor load values was taken as .30, and criteria for distinctiveness was taken as $p<.001$. If EFA conducted to test structure validity of the scale, it was determined that the initial scale form explained $45.157 \%$ percent of the total variance and two-factor structure of the scale was verified. Then, in EFA repeated after removing some items from the scale, a two-dimensional structure explaining $47.959 \%$ of the total variance was obtained. As a result of testing factors obtained in EFA with CFA, it was concluded that EFA also obtained as a result of testing with DFA model fit factors values, concluded that model fit values were sufficient $(X 2=303.73 ; \mathrm{sd}=187 ; \mathrm{X} 2 / \mathrm{sd}=1.62 ; \mathrm{RMSEA}=$ 0.06; $\mathrm{CFI}=0.96 ; \mathrm{GFI}=0.85 ; \mathrm{AGFI}=0.82 ; \mathrm{SRMR}=0.06 ; \mathrm{NFI}=0.91$ ). In the resulting model, it can be said that factors were approved through data, the scale's two-dimensional structure was verified, and the scale was applicable. In determining internal validity of the scale, $27 \%$ top and bottom groups were evaluated with 'independent group $t$ test' and it was concluded that the difference was statistically significant $(p<0.001)$. For reliability of the scale, the Cronbach's alpha reliability method was used, and it was calculated as 0.92 for intrinsic motivation; 0.82 for extrinsic motivation; and 0.94 for overall scale. Findings related to validity and reliability of the adult motivation scale show that measurement tool was at acceptable level values psychometrically. Adult Motivation scale consists of 2 parts including intrinsic and extrinsic motivation scales. Intrinsic motivation dimension consists of 13 questions including 4-7-8-9-10-12-13-14-15-17-19-20-21 numbers; and extrinsic motivation dimension consists of 8 questions including 1-2-3-5-6-11-16-18 numbers. High scores obtained from the scale mean that level of motivation is high. It can be said that there are limited number of studies on motivation in Turkey, and there is a need for motivation researches towards different generations, cultures, levels of education and professional fields. In addition, determining level of individuals' motivation and their tendencies can be said to bear importance in individualistic and organizational sense. For these reasons, it is considered that the scale can be used in future studies and will contribute to the researchers. 


\section{Giriş}

İnsanın; toplumun temel yapı taşı ve örgütün önemli bir kaynağı olarak görülmesinin ve insanla ilgili faktörlerin; birey, örgüt ve toplum için önem taşıdığının anlaşıımasının, motivasyonu önemli bir araştırma konusu haline getirdiği söylenebilir. Motivasyon genelde, "davranışı harekete geçiren, yönlendiren ve devam ettiren bir süreç" olarak tanımlanmaktadır (Hoy ve Miskel, 2010: 157). Alan yazında zaman zaman motivasyonun güdülenme anlamına geldiği ve güdülenme kavramının, motivasyon yerine kullanıldığı görülmektedir (Aydın, 2013; Baymur, 1994; Cüceloğlu, 1996; Erdem, 2015; Eren, 2015; Gürgan, 2016; Özkalp ve Kırel, 2016; Sabuncuoğlu ve Tüz, 1998; Sağır, 2016; Uğurlu, 2016). Fakat motive etme, güdünün ötesinde bir kavramdır ve bir kişiye bir eylemi yapması için gerekli güdü ve dürtüleri sağlamak anlamına gelir (Adair, 2006: 17). Güdüler motivasyonun özünü oluşturur ve insan davranışlarında etkili bir role sahiptir. Çünkü davranışlar güdüler tarafindan yönetilir (Sabuncuoğlu ve Vergiliel Tüz, 2013). Sabuncuoğlu ve Tüz $(1998,2013)$ güdüleri; oluşma biçimleri, yönleri ve şiddetleri gibi ölçütlere dayanarak; içgüdü, fizyolojik, sosyal ve psikolojik güdü gibi dört başlık altında incelemiştir. Ayrıca, yeni doğacak gereksinimlerin güdüleri yeniden uyardığını, bunun da güdülerin dinamik bir yapıya sahip olmasını sağladığını belirtmiştir. Bu nedenle; motivasyonun kaynağı gereksinmelerdir. Gereksinmelerin ilginç yönü ise, kişilere göre değişkenlik göstermesi ve bireyin kişilik yapısının, sosyal çevredeki yerinin, eğitsel ve kültürel düzeyinin, bireyin gereksinmelerinin yönünü ve biçimini belirleyebilmesidir (Sabuncuoğlu ve Tüz, 1998; Sabuncuoğlu ve Vergiliel Tüz, 2013). Baymur’a göre (1994) duygu ve heyecanlar insan davranışlarının, uyum ve uyumsuzlukların önemli etmenleri arasında yer alır. Bunlar, ihtiyaçlarla ve güdülerle sıkı ilişkisi içindedir. Bu bilgilerden hareketle ihtiyaçların güdüleri, güdülerinde davranışları etkileyen bir döngü içinde yer aldığı; ihtiyaç ve davranışlarla motivasyon arasında ilişki olduğu söylenebilir. Bu nedenle motivasyon, insan yaşamıyla ilgili dinamik ve değişken bir kavram olarak nitelenebilir.

İhtiyaçlar, inançlar ve hedefler motivasyonun önemli ögeleridir (Hoy ve Miskel, 2010). Motivasyonun çoğu doğrudan ve dolaylı olarak bedensel intiyaçlardan kaynaklansa da, bir kısmı ruhsal ihtiyaçlarımızdan kaynaklanır (Adair, 2006). Sabuncuoğlu ve Vergiliel Tüz (2013) sosyal güdülerin psikolojik güdülerden daha etkili olabileceğine ve psikolojik güdüleri analiz etmenin fizyolojik ve sosyal güdülerden zor olduğunu belirtmiştir. Bu nedenlerle; sadece fizyolojik değil, psikolojik ve sosyal intiyaçların da bireyin motivasyonunda önemli olduğu, fakat bunları tespit etmenin ve gidermenin fizyolojik intiyaçlara kıyasla zor olabileceği söylenebilir. Bu durumun sebebi, psikolojik ve sosyal intiyaçların bireysel olarak farklılaşması, bireysel algının duygu ve düşüncelerden etkilenmesi olabilir. Son yıllarda yapılan nörolojik araştırma sonuçlarında da, algıların hızla ve bilinçsiz bir şekilde duygulardan etkilendiği görülmektedir (Mc Shane ve Von Glinow, 2016).

Motivasyon, insanların yaptıkları işten ve iş çevresinden memnun olduklarında daha verimli çalışacak olmaları nedeniyle örgütler için araştırma konusu olmuştur (Eren, 2015). Yapılan araştırmalarda motivasyonun örgütler için taşıdığı öneme ve verimlilik, performans üzerindeki etkisine dikkat çekilmiştir. Örneğin, örgütsel-yönetsel motivasyon uygulamalarının verimlilik ve performans (Onay ve Ergüden, 2011; Ölçer, 2005), kişisel verim ve başarı (Aytürk, 2010) üzerinde etkili olduğunu gösteren araştırmalar bulunmaktadır. Performans, araştırmacılar tarafindan; yetenek ile motivasyonun çarpımı şeklinde formüle edilmekte ve motivasyon üstündeki güçlü etkisine, örgütlerde insanlar üzerindeki stratejik önemine dikkat çekilmektedir (Hitt, Miller ve Colella, 2006). Bu bilgiler ışığında, en yetenekli kişinin bile yeterli motivasyona sahip olmadığı sürece yüksek performans gösteremeyeceği söylenebilir.

Örgütlerde birey; temel fizyolojik, gelişme-kendini gerçekleştirme intiyacı ve bir gruba üye olma ve yarar sağlama isteği duyarken, diğer yandan ise örgüt amaçlarına ulaşmak istemekte, hedeflerine ulaşma ve ayakta kalma mücadelesini sürdürmektedir. Bu iki amaç grubu arasında uyumun sağlanması; kişi ve kurum adına tatmin edici sonuçlar vermektedir. Bu uyumun sağlanmasında ise, motivasyon temel anahtar rol oynar (Fındıkçı, 2012: 368). Bu nedenle, motivasyon yalnızca Türkiye'deki örgütlerde değil hemen hemen tüm dünyadaki örgütlerde en önemli yönetim sorunlarından biri olarak kabul edilmektedir (Öztürk, 2013). Bir örgütün amacına ulaşmasında ve başarısında kritik role sahip olan insanın (Öge, 2016) motivasyonunun örgüt ve birey için taşıdığı önem düşünüldüğünde, yüksek motivasyonun bireyin hayatnı olumlu yönde etkileyeceği söylenebilir. Motivasyon bireysel ve örgütsel anlamda performans ve verimlilik dışında birçok farklı kavramla da ilişkilidir. Örneğin, akademik başarıda (Byrnes, 2011; Akbaba, 2006) önem taşır. İş doyumunu etkiler (Ağırbaş, Çelik ve Büyükkayıkçı, 2005; Yavuz ve Karadeniz, 2009; Toker, 2006) ve stresle ilişkilidir (Ersarı ve Naktiyok, 2012).

Motivasyonu açıklamaya çalışan farklı kuramlar bulunmakta ve bu kuramlar genelde iki grupta incelenmektedir. Bunlardan ilki; klasik, geleneksel, içerik ve kapsam kuramları olarak farklı şekillerde adlandırılmıs olup, insanda motivasyonun nedenlerini; ikinci grupta yer alan kuramlar ise çağdaş, modern, süreç kuramları olarak adlandırılmış olup motivasyonun oluşum aşamalarını araştırmaktadır (Hitt, Miller ve Colella, 2006; Koçel, 2005; Mullins, 2006; Onay ve 
Ergüden, 2011; Sağır, 2016). Bir başka ifadeyle, kapsam kuramları bireyi "neyin" motive ettiği; süreç kuramları bireyin "nasıl" motive olduğu sorusuyla ilgilenmektedir (Şeker, 2015; Yücel ve Gülveren, 2016). Motivasyonu daha çok içsel faktörlerle ifade eden kapsam ve dışsal faktörlerle ifade eden süreç kuramları (Sağır, 2016) arasındaki temel fark, bireyin eyleme geçmedeki mantı̆̆ıdır (Hoy ve Miskel, 2010). Motivasyon teorilerindeki çeşitliliğin kavramsal kargaşa yaratacă̆ı (Leonard, Beauvais ve School, 1999), içsel ve dışsal motivasyon ayrımının incelemeyi kolaylaştracağı düşünülebilir. Yirminci yüzyılda motivasyon konusunda sıkça söz edilen kavramlardan dışsal motivasyon, davranış psikolojisi ile ilgili olup, bireyin dıştan kontrol edildiğini savunurken; içsel motivasyon, bilişsel ve hümanist psikoloji ile ilgili olup içsel düşüncelerin, duyguların ruhsal enerjisini vurgulamaktadır (Aydın, 2013). Bu nedenle araştırmada kapsam, süreç ve Öz-Belirleme kuramında yer alan içsel, dışsal motivasyon (Deci, Ryan ve Williams, 1996; Rigby, Deci, Patrick ve Ryan, 1992; Ryan ve Deci, 2000 a; Ryan ve Deci, 2000 b) ayrımından yararlanılmıştır.

\section{Araştırmanın Amacı ve Önemi}

Araştırmacılar tarafindan yetişkinlik döneminin başlangıç yaşı 18-20-25 li yaşlar, bitiş yaşı 60-65 li yaşlar olarak farkIı şekillerde ifade edilmektedir (Onur, 1997). Bu yaş dönemlerinin; bireyin hayatının önemli bir kısmını kapsadığı ve üretkenliğin dolayısıyla da ülke ekonomisine katkısının arttğı yıllar olduğu söylenebilir. Alan yazın tarandığında motivasyonu ölçmek için kullanılan ölçüm araçlarının az olduğu ve genelde sınırlı alanda kullanıldığı görülmektedir. Yaşam boyu öğrenmenin bir hayat biçimi haline geldiği günümüzde, yetişkin bireyin motivasyonun sadece işte değil akademik hayatında da önemli olduğu söylenebilir. Bu nedenle farklı; eğitim kademelerinde, akademik ve iş çevrelerinde bulunan 20-60 yaş arasındaki bireyler için kullanılabilecek "yetişkin motivasyon ölçeği" ne ihtiyaç duyulduğu düşünülmektedir. Bu açıdan, geliştirilecek ölçeğin alana ve araştırmacılara katkı sağlaması beklenmektedir.

\section{Yöntem}

\section{Katilımcilar}

Ölçme aracı geliştirmede örneklem büyüklüğü konusunda alanyazında görüş birliği bulunmamaktadır. Örneklem sayısının en az 300, ya da soru sayısının en az 5-10 kat olması gerektiği görüşünün genel kabul gördüğü söylenebilir (Seçer, 2015). Tarama modelinde yürütülen bu araştırma, kolay ulaşılabilir örneklem yöntemiyle 2017 yılında Bartın ilindeki gerçekleştirilmiştir. Katılımcı sayısı ön uygulamada 23, açımlayıcı faktör analizinde 345, doğrulayıcı faktör analizinde 173 tür. Çalışma grubu 364 mühendislik fakültesi öğrencisi, 143 öğretmen, 34 sağlık ve hukuk alanında çalışan olmak üzere toplamda en az ilkokul mezunu olan 20-60 yaşları arasındaki 541 kişiden oluşmaktadır.

\section{Motivasyon Ölçeği Geliştirme Süreci}

Çalışmada ölçeğin geliştirilme sürecinde; alan yazın taranmış, geliştirilen benzer ölçekler incelenmiştir. İncelemeler sonucunda, özellikle Ryan ve Deci'nin (2000 a) motivasyon sınıflandırmasındaki üç boyutu kapsayan 35 soruluk madde havuzu oluşturulmuştur. Maddelerle ilgili, Türkçe eğitiminde ve ölçme değerlendirmede iki, psikolojik danışmanlık alanında bir olmak üzere toplamda beş uzmandan görüş alınmıştır. Alınan görüşlerde, dört uzmanın da, iki maddenin ayırt ediciliğinin düşük olacağını bildirmesi üzerine ilgili maddeler çıkarılarak ölçek maddeleri 33’e düşürülmüştür. Araştırmada, maddelerin anlaşııırlığını test etmek için 23 üniversite öğrencisi ile yapılan ön uygulamada genelinin üç maddeyi farklı yorumlandığı anlaşılmış ve bu maddeler çıkarılarak 30 maddelik ölçek oluşturulmuştur. Uzman görüşünde ve öğrenci ön uygulamasında sorun tespit edilen maddeler genel olarak incelendiğinde; soruların tamamının motivasyonsuzlukla ilgili olduğu görülmüş ve bu boyut çıkarılmıştır. Böylece, ölçekte içsel motivasyon boyutunda 18 , dışsal motivasyon boyutunda 12 madde yer almıştı. Ölçekte "kesinlikle katılmıyorum", "katılmıyorum", "orta derecede katılıyorum", "katılıyorum" "kesinlikle kathlıyorum" şeklinde beşli likert tipi ölçme formu kullanılmıştır.

\section{Verilerin Analizi}

Verilerin analizi yapılmadan önce uç, eksik ve hatalı değerler incelenmiş ve veri setinin normalliğini etkileyeceği düşünülen 7 kişiye ait form verilerden çıkarılmıştı. Araştırmada verilerin faktör analizine uygun olup olmadığı Kaiser-Meyer-Olkin (KMO) örneklem yeterliliği ve Barlett küresellik testleri ile incelenmiştir. Ölçeğin yapı geçerliliğini tespit etmede; açımlayıcı faktör analizi (AFA), bu analiz sonucunda ulaşılan faktör yapısının doğruluğunu test etmede doğrulayıcı faktör analizi (DFA) uygulanmıştr. Ölçeğin kapsam geçerliği için uzman görüşünden yararlanılmıştr. Ölçeğin güvenilirlik çalışmasında ise, iç tutarlık (Cronbach Alpha) değerleri hesaplanmıştır. Ayrıca, madde toplam puan korelasyonu ve \% 27 lik alt-üst grup karşılaştırması yapılmıştır. AFA da elde edilen ölçeğin model uyumu DFA ile incelenmiştir. DFA da çoklu uyum indeksleri ( $\mathrm{X}^{2}$, sd, $\mathrm{X}^{2}$ /sd, RMSEA, CFI, GFI, AGFI, SRMR, NFI) kullanılmıştır. 


\section{Bulgular ve Yorumlar}

\section{Geçerlik}

Büyüköztürk'e (2011: 168) göre; geçerlik teknikleri içinde kapsam, ölçüt bağımlı ve yapı geçerliği yer alır. Kapsam geçerliğinde, uzman görüşüne başvurma daha çok tercih edilir. Yapı geçerliğini incelemede ise; faktör, küme ve iç tutarlık analizi ve hipotez testi tekniklerinden yararlanılır. Bu araştırmada, ölçeğin geçerliği kapsam, yapı ve iç geçerlik açısından incelenmiştir. Kapsam geçerliğine yönelik olarak ölçek geliştirme sürecinde uzman görüşü alınmış, yapı geçerliğinde faktör analizi, iç tutarlığın tespitinde alt-üst grup karşılaştırması ve Cronbach yapılmıştır.

\section{Yapı Geçerliliği}

Faktör analizi öncesinde ölçeğin madde toplam korelasyonları incelenmiştir. Yapılan analizler sonu elde edilen bulgular Tablo 1' de sunulmuştur.

\section{Tablo 1. Madde Analizi Sonuçları}

\begin{tabular}{|c|c|c|c|}
\hline Madde Numarası & Maddde toplam Korelasyonu & t Alt - Üst Grup ( \% 27) & \\
\hline m1 & 0.55 & 10.65 & $*$ \\
\hline m2 & 0.67 & 12.37 & * \\
\hline m3 & 0.56 & 10.54 & $*$ \\
\hline m4 & 0.46 & 8.04 & $*$ \\
\hline m5 & 0.67 & 12.25 & $*$ \\
\hline m6 & 0.70 & 15.02 & $*$ \\
\hline m7 & 0.50 & 10.87 & $*$ \\
\hline $\mathrm{m} 8$ & 0.42 & 8.30 & $*$ \\
\hline m9 & 0.55 & 9.50 & * \\
\hline m10 & 0.47 & 8.93 & * \\
\hline m11 & 0.72 & 12.68 & $*$ \\
\hline $\mathrm{m} 12$ & 0.63 & 12.10 & $*$ \\
\hline $\mathrm{m} 13$ & 0.67 & 11.76 & * \\
\hline m14 & 0.45 & 8.96 & * \\
\hline m15 & 0.68 & 11.29 & $*$ \\
\hline m16 & 052 & 11.96 & $*$ \\
\hline m17 & 0.60 & 12.16 & $*$ \\
\hline m18 & 0.63 & 11.34 & * \\
\hline m19 & 0.72 & 13.38 & * \\
\hline $\mathrm{m} 20$ & 0.71 & 12.17 & $*$ \\
\hline m21 & 0.48 & 9.37 & $*$ \\
\hline $\mathrm{m} 22$ & 0.54 & 8.29 & * \\
\hline $\mathrm{m} 23$ & 0.57 & 10.86 & $*$ \\
\hline m24 & 0.51 & 11.80 & $*$ \\
\hline $\mathrm{m} 25$ & 0.68 & 14.37 & $*$ \\
\hline m26 & 0.64 & 11.76 & $*$ \\
\hline $\mathrm{m} 27$ & 0.56 & 9.50 & * \\
\hline $\mathrm{m} 28$ & 0.63 & 12.30 & $*$ \\
\hline m29 & 0.69 & 11.89 & $*$ \\
\hline \multirow[t]{2}{*}{$\mathrm{m} 30$} & 0.66 & 11.72 & $*$ \\
\hline & & $\begin{array}{lr}\left({ }^{1}\right) \mathrm{n}=345 & * \mathrm{p}<0.01 \\
\left(^{2}\right) \mathrm{n} 1-\mathrm{n} 2=94 & \mathrm{t}>2.56\end{array}$ & \\
\hline
\end{tabular}

Yapılan analizlerde, madde toplam korelasyonu katsayılarının 0.42 ile 0.72 ; t değerlerinin 8.04 ile 15.02 arasında değiştiği görülmektedir. Madde toplam korelasyonu katsayılarının, Cronbach Alfa değerlerinin ve \% 27 lik alt-üst gruptaki katlımcıların $t(t>2.56)$ değerlerinin birlikte değerlendirilmesi sonucunda ölçekten hiçbir madde çıkarılmamıştr. Anaizlerde faktör yük değerleri için kabul noktası 0.30 , ayırt edicilik için ölçüt $p<0.01$ olarak alınmıştır. 


\section{Açımlayıcı Faktör Analizi}

Araştırmada, veri setinin çok değişkenli istatistikler için uygun olup olmadığı Kaiser-Meyer Olkin (KMO) örneklem yeterliliği ve Barlett küresellik testi ile faktör analizi öncesinde incelenmiştir. KMO örneklem yeterliği istatistiği sonuçları, maddeler arası korelasyonların faktör analizine uygun olduğunu göstermiştir (KMO=0.94). KMO değerinin 0.50 den düşük olması durumunda faktör analizine devam edilemeyeceği, 0.90 üstü olması ise mükemmel olduğu şeklinde yorumlanır (Çokluk, Şekercioğlu ve Büyüköztürk, 2012; Şencan, 2005). Ayrıca Barlett Küresellik Testi de maddeler arasında faktör analizi için yeterli ilişki olduğunu göstermektedir $\left(X^{2}=4982,53 ; p<0,01\right)$. Bu bulgulardan hareketle ölçeğin deneme formunun verilerinin faktör analizine uygun olduğu söylenebilir.

Ölçeğin geliştirilmesinde Ryan ve Deci'nin (2000a) motivasyon sınıflandırması esas alınarak madde havuzu oluşturulmuştur. Bu nedenle de, içsel-dışsal alt faktörlerin birbiriyle ilişkisiz olduğu varsayılmış ve ölçeğin yapı geçerliğini belirlemek için varimax döndürme ile temel bileşenler analizi kullanılarak AFA yapılmıştır. Ayrıca AFA öncesinde yapılan incelemelerde; ortalama (3.83), ortanca (3.90) ve tepe değerin (3.83) birbirine yakın olması, histogram grafiği'nin simetriğe benzemesi, çarpıklık (-1.13; Std. Hatası: 0.13), basıklık (1.83; Std. Hatası: 0.26) katsayılarının incelenmesi sonucunda, ölçeğin normal dağıldığına karar verilmiştir. AFA sonucunda ise, ölçeğin özdeğeri 1'den büyük \% 5 varyansa sahip iki boyutlu bir yapıya sahip olduğu görülmüştür. Yamaç birikinti grafiğinin ve alanyazının incelenmesi sonucunda faktör sayısı iki ile sınırlandırılarak analizler tekrarlanmıştır. Ölçeğin iki faktörlü yapısına yönelik yapılan analizde elde edilen bulgular incelendiğinde birinci faktörün toplam varyansın \% 40.01'ini, ikinci faktörün \% 5.14'ünü açıkladığı, iki faktörün birlikte toplam varyansın \% 45.15'ini açıkladığı belirlenmiştir. Alanyazında ölçeğin açıklaması gereken varyans oranları konusunda farklı görüşler bulunmaktadır. Bu görüşlerin genelde \% 50 üstü şeklinde olduğu söylenebilir. Fakat, özellikle sosyal bilimlerde ölçek geliştirmede bu rakamlara ulaşmak güçtür. Bu nedenle çok faktörlü desenlerde \% 40 ile \% 60 arası yeterli olarak kabul edilir (Çokluk, Şekercioğlu ve Büyüköztürk, 2012: 197). Faktörler belirlendikten sonra maddelerin hangi faktörde yer aldığını belirlemek amacıyla faktör analizi yapılmıştır. Faktörleri oluşturan maddeler, yük değerleri, ölçeğin son halinin özdeğer ve varyans oranları Tablo 2'de verilmiştir.

Tablo 2. Faktör Yük Değerleri ve Ortak Varyansı

\begin{tabular}{|c|c|c|}
\hline Madde Numarası & Faktör 1 & Faktör 2 \\
\hline $\mathrm{m} 11$ & 0.77 & \\
\hline m5 & 0.74 & \\
\hline m29 & 0.71 & \\
\hline $\mathrm{m} 13$ & 0.68 & \\
\hline m17 & 0.66 & \\
\hline m20 & 0.66 & \\
\hline $\mathrm{m} 12$ & 0.64 & \\
\hline m9 & 0.64 & \\
\hline m15 & 0.63 & \\
\hline m19 & 0.63 & \\
\hline $\mathrm{m} 23$ & 0.62 & \\
\hline $\mathrm{m} 28$ & 0.61 & \\
\hline m26 & 0.61 & \\
\hline m3 & & 0.76 \\
\hline m24 & & 0.70 \\
\hline m14 & & 0.62 \\
\hline m7 & & 0.59 \\
\hline m4 & & 0.55 \\
\hline $\mathrm{m} 22$ & & 0.51 \\
\hline m1 & & 0.48 \\
\hline $\mathrm{m} 8$ & & 0.40 \\
\hline Özdeğer & 8.57 & 1.49 \\
\hline Varyans (\%) & 40.85 & 7.10 \\
\hline Açıklanan Toplam Varyans & \multicolumn{2}{|c|}{47.95} \\
\hline
\end{tabular}

| Kastamonu Eğitim Dergisi, 27(2), 2019| 
Tablo 2'de görüldügü gibi maddelerin faktör yükleri 0.40 ile 0.77 arasında değişmektedir. Araştırmacılar tarafindan faktör yük değerlerinin örneklem büyüklüğünü de dikkate alarak 0.30 olması yönünde yaygın bir görüş olmakla birlikte, 0.40 olması (Şencan, 2005) ya da, 0.32'den küçük olmaması gerektiğini (Çokluk, Şekercioğlu ve Büyüköztürk, 2012: 194; Seçer, 2015: 87) savunanlarda bulunmaktadır. Bir maddenin birden fazla boyutta 0.32 ve üstünde yük değerine sahip olması durumunda söz konusu boyutlarda faktör yük değerleri arasında 0.10 , ideal olarak ise 0.20 düzeyinde bir fark olması beklenir (Seçer, 2015: 87). Bu nedenlerle, araştırmada faktör yük değerinin 0.32'nin altında olmamasına, binişiklik gösteren maddeler arasında en az 0.20 fark olmasına dikkat edilmiştir. Yapılan değerlendirmeler sonucunda ise (2-6-10-16-18-21-25-27-30) maddelerin çıkarılmasına karar verilmiştir. ilgili maddeler çıkarıldıktan sonra; toplam varyansın \% 40.85'ini açıklamayan birinci faktör soru içerikleri dikkate alınarak içsel motivasyon olarak, \% 7.10'ını açıklayan ikinci faktör ise, dışsal motivasyon olarak adlandırılmıştır.

Araştırma kapsamında elde edilen veriler iç geçerlik açısından karşılaştırmak amacıyla alt \% 27 ve üst \% 27 grupların madde ortalama puanları arasındaki farklar ilişkisiz t testi ile incelenmiştir. Bu analizde gruplar arasında farkların anlamlı çıkması testin iç geçerliğinin (tutarlıı̆̆ıın) bir göstergesi olarak değerlendirilir (Büyüköztürk, 2011: 168). Testin iç geçerliğine ilişkin veriler Tablo 3'de verilmiştir.

Tablo 3. İç Geçerlik Verileri

\begin{tabular}{lcccc}
\hline & N & Ort \pm SS & T & P \\
\hline Alt Grup (\% 27) & 94 & $3.06 \pm 0.56$ & 22.91 & $<0.01$ \\
Üst Grup (\% 27) & 94 & $4.48 \pm 0.20$ & & \\
\hline
\end{tabular}

Tablo 3'deki iç geçerlikle ilgili bulgular incelendiğinde alt grupla üst grubun puanlarının aritmetik ortalamaları arasındaki fark istatistiksel olarak anlamlı bulunmuştur $(p<0.01)$. Elde edilen bulgulara göre, yetişkin motivasyon ölçeğinin yüksek ve düşük motivasyon gösterenleri birbirinden ayırdığı ve iç geçerliğe sahip olduğu söylenebilir.

\section{Doğrulayıcı Faktör Analizi (DFA)}

Ölçeğin iki faktörden oluşan yapıya sahip olduğunu doğrulamak amacıyla DFA yapılmıştr. Yetişkin motivasyon ölçeğine ilişkin birinci düzey DFA uygulaması Şekil 1'de, DFA Uyum Değerleri Tablo 4'de verilmiştir.

Şekil 1 incelendiğinde; içsel ve dışsal motivasyon alt boyutları arasında ilişki olduğu, tüm maddelerin geçerlik katsayılarının $(0.42-0.81)$ arasında değiştiği ve geçerli olduğu $(r>0,30)$ görülmektedir. Ölçeğin t değerlerinin ise, $(5.35-12.33)$ arasında değiştiği $(t>2,56)$ tespit edilmiştir. Bu nedenle ölçeğin tüm maddelerinin 0.01 düzeyinde anlamlı olduğu söylenebilir. Ayrıca, hesaplanan modifikasyon indeksleri incelendiğinde madde 13 (ölçeğin son formunda madde 10) "Keyif aldığım şeyleri yapmaya devam ederim" ile madde 19'un (son formda madde 14) "Yaptıklarımın sonucunda yaşadığım mutluluk benim için önemlidir” ölçekte aynı gizil değişken altında yer aldığı ve birbiriyle ilişkili olduğu görülmektedir.

Tablo 4. Yetişkin Motivasyon Ölçeği Doğrulayıcı Faktör Analizi Uyum Değerleri

\begin{tabular}{lllllllll}
\hline Model & $\chi^{2}$ & $\left(\chi^{2} / s d\right)$ & RMSEA & SRMR & NFI & CFI & GFI & AGFI \\
\hline Birinci Düzey & 303,73 & 1,62 & 0,06 & 0,06 & 0,91 & 0,96 & 0,85 & 0,82 \\
\hline
\end{tabular}

Uyum iyiliği indekslerinin incelenmesinde farklı sınıflandırmalar görülmektedir. Kline (2005) büyük örneklemlerde $X^{2} / s d \leq 3$ olması mükemmel uyumun, Hu ve Bentler (1998) $R M S E A \leq 0.06, S R M R \leq 0.08$ olmasının iyi uyumun, Byrne (2010) GFI, AGFI, CFI, NFI değerlerinin 0.90 ve daha büyük olmasının kabul edilebilir uyumun göstergesi olduğunu ifade etmiştir. DFA ile sınanan modelin Tablo 4'deki uyum indeksleri incelendiğinde $\left(X^{2}=303.73 ; s d=187 ; X^{2} / s d=1.62 ; R M\right.$ $S E A=0.06 ; C F I=0.96 ; G F I=0.85 ; A G F I=0.82 ; S R M R=0.06 ; N F I=0.91) \mathrm{GFI}$ ve NFI değerlerinin kabul edilebilir değerlerden biraz düşük olduğu fakat diğer tüm değerlerin iyi uyum düzeyinde olduğu söylenebilir. Elde edilen modelde; faktörlerin veriler ile onaylandığı, ölçeğin iki boyutlu yapısının doğrulandığı ve ölçeğin uygulanabilir olduğu söylenebilir. 


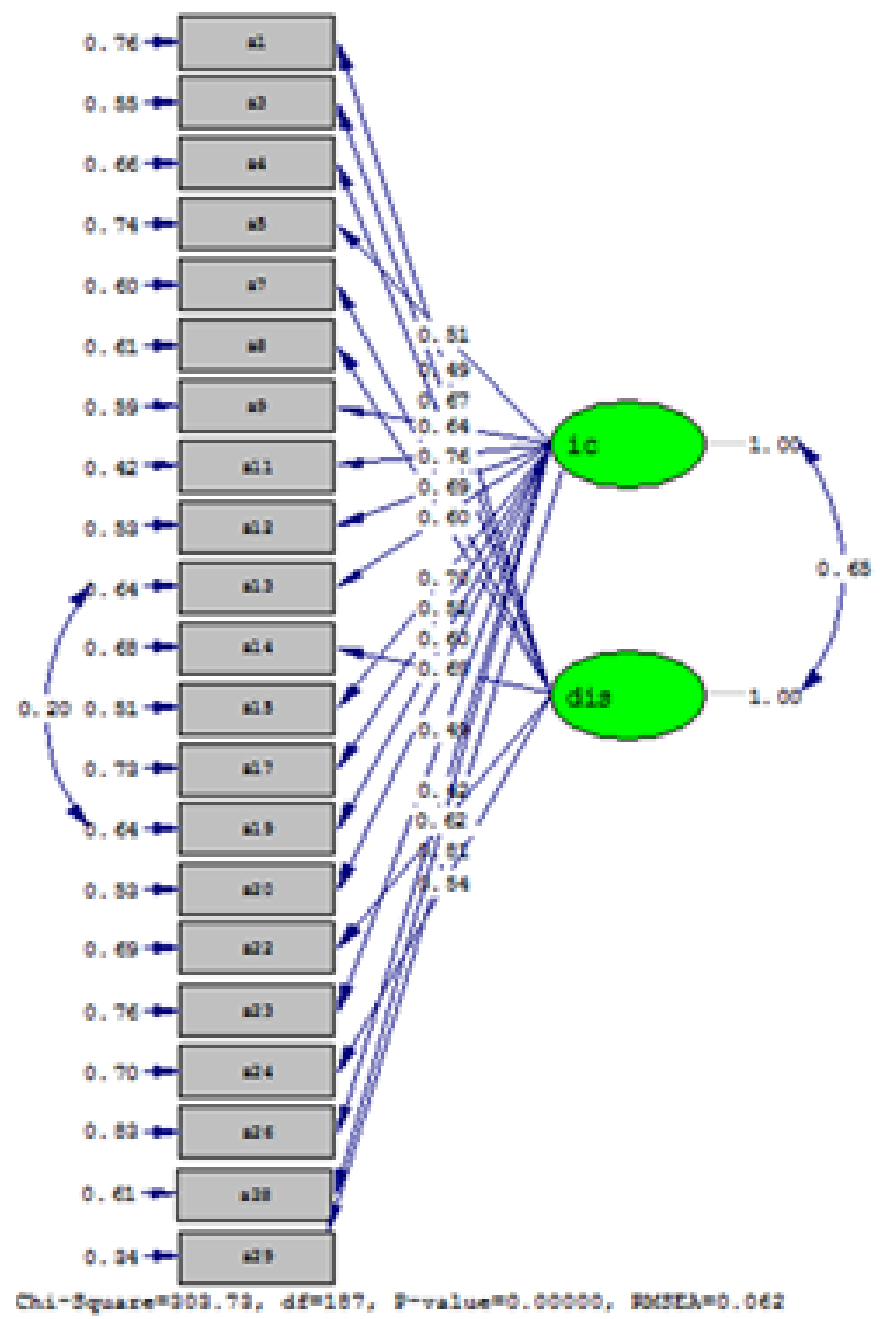

\section{Şekil 1. Dışsal Motivasyon Birinci Düzey DFA}

\section{Güvenirlik}

Testin ölçmek istediği özelliği ne derece doğru ölçtüğü ile ilgili olan güvenirlik katsayısının psikolojik bir test için 0.70 ve daha yüksek olması genelde yeterli görülmektedir (Büyüköztürk, 2011: 171). Yetişkin motivasyon ölçeğinin güvenirliğini belirlemek amacıyla iç tutarlılık katsayısı (Cronbach Alfa) hesaplanmıştır. Araştırmada, Cronbach Alfa değeri içsel motivasyon için; 0.92, dışsal motivasyon için; 0.82, ölçeğin geneli için; 0.94 olarak hesaplanmıştr. Bu değerler, ölçekteki maddelerin güvenirliklerinin yüksek ve aynı tutumu ölçmeye yönelik olduğunu göstermektedir.

\section{Tartışma}

Bu çalışmada, yetişkinlerin motivasyonlarını belirlemek amacıyla bir ölçek geliştirilmiştir. Bu amaçla Ryan ve Deci'nin (2000a) sınıflandırması esas alınarak, alan yazın ve uzman görüşü doğrultusunda madde havuzu oluşturulmuştur. Ölçeğin yapı geçerliğini tespit etmek amacıyla AFA yapılmıştır. Otuz maddeden oluşan ilk ölçek formunun toplam varyansın \% 45.15'ini açıkladığı tespit edilmiş ve ölçeğin iki faktörlü yapısı doğrulanmıştır. Ardından bazı maddelerin ölçekten çıkarıldıktan sonra tekrarlanan AFA de toplam varyansın \% 47.95'ini açıklayan iki boyutlu bir yapı elde edilmiştir. AFA de elde edilen faktörlerin DFA ile test edilmesi sonucunda model uyum değerlerinin genelde iyi olduğu sonucuna ulaşılmıştır. Yetişkin motivasyon ölçeğinin geçerliği ve güvenirliği ile ilgili bulgular, ölçme aracının psikometrik olarak kabul edilebilir düzeyde değerlerde olduğunu göstermektedir. Yetişkin Motivasyon ölçeği içsel ve dışsal motivasyon alt boyutu olarak 2 bölümden oluşmaktadır. İçsel motivasyon boyutu; 4-7-8-9-10-12-13-14-15-17-19-20-21 numaralı 13 sorudan oluşup güvenirlik değeri 0.92'dir. Dışsal motivasyon boyutu ölçekte yer alan; 1-2-3-5-6-11-16-18 numaralı 8 sorudan oluşmakta olup güvenirlik değeri $0.82^{\prime}$ dir. Ölçeğin toplamı 21 madde olup güvenirlik değeri 0.94 'tür. Ölçekte elde edilen puanın yüksek olması motivasyon düzeyinin yüksek olduğu anlamına gelmektedir.

İnsan tutum ve davranışlarının tespit edilmesinin zorluğu motivasyon araştırmalarını güçleştirmektedir. Ayrıca, farklı 
ülkelerde geliştirilen ölçekler kültürel farklııklar nedeniyle motivasyon konusunda doğru tespitler yapılmasını zorlaştırmaktadır. Çünkü bireyi motive eden faktörler; kişisel, sosyal ve kültürel farklılılar gösterebilir. Alanyazında, farklı kültürlerden gelen çalışanların farklı biçimlerde motive edilebileceğini (Hofstede, 1980) ulusal kültür boyutları ile bireylerin motivasyon düzeyleri arasındaki ilişki olduğunu (örneğin; Demir ve Okan, 2009) gösteren araştırmalar bulunmaktadır. Motivasyon kültürlerarası farklıık gösterdiği gibi kuşaklar arası da farklılık gösterebilmektedir. Çünkü, her kuşağın kendine özgü özellikleri, değer yargıları, tutumları, güçlü ve zayıf yönleri bulunmaktadır (Lower, 2008). Bu nedenle de, farklı yaş gruplarının bir arada çalıştğı günümüz örgütlerinde yaşanan sorunların büyük kısmı; kuşaklararası algı, yöntem, uygulama ve iletişim farklılıklarından kaynaklanmaktadır (Keleş, 2011: 129). Her birey farklı olduğu için, bireyi motive eden faktörler de farklılık gösterir (Coşkun, 2015). Bu nedenle motivasyon araçlarının ve bireye olan etkilerinin, çalışanların bireysel niteliklerini ve ihtiyaçlarını göz önüne alarak saptanması gerekir (Onay, ve Ergüden, 2011).

Araştırmalarda motivasyonun; verimlilik ve performans (Onay ve Ergüden, 2011; Ölçer, 2005), kişisel verim ve başarı (Aytürk, 2010), akademik başarı (Byrnes, 2011; Akbaba, 2006), iş doyumu (Ağırbaş, Çelik ve Büyükkayıkçı, 2005; Yavuz ve Karadeniz, 2009; Toker, 2006), stres (Ersarı ve Naktiyok, 2012) üzerindeki etkisi, duygusal zeka ve örgütsel bağlılıkla (Tulunay Ateş ve Buluç, 2015) ilişkisi ortaya çıkarılmıştır. Araştırma sonuçlarından hareketle, motivasyonla ilgili iyileştirmelerin; bireyin başarııını ve sağlığını olumlu yönde etkileyeceği söylenebilir. Ayrıca, çalışma yaşamı ile yaşam doyumu arasındaki güçlü ilişki (Keser, 2005) nedeniyle; çalışma doyumu yüksek üretken bireylerin yaşam doyumlarının, dolayısıyla da; toplumsal refaha, huzura ve mutluluğa katkılarının artacağı düşünülebilir.

Örgüt ve birey ihtiyaçları arasındaki uyumda anahtar rol oynayan (Fındıkçı, 2012) motivasyon konusunda Türkiye'de yapılan araştırmalar incelendiğinde; bu araştırmaların sınırlı sayıda olduğu ve farklı kuşaklara, kültürlere, eğitim düzeylerine, çalışma alanlarına yönelik motivasyon araştırmalarına intiyaç duyulduğu görülmektedir. Bu nedenle, ölçeğin yapılacak araşttrmalarda kullanabileceği ve araştırmacılara katkı sağlayacağı düşünülmektedir. Farklı özelliklerde, yaşlar$\mathrm{da}$, öğrenim kademelerinde ve iş kollarındaki yetişkinlerde motivasyonun incelenmesiyle, motivasyonsuzluğu önleyici ve motivasyonu geliştirici çalışmalar yapılabilecektir.

\section{Kaynakça}

Adair, J. (2006). Etkili Motivasyon. (çev. Uyan, S.). İstanbul: Babıali Kültür Yayıncılığı.

Ağırbaş, I., Çelik, Y. ve Büyükkayıkçı, H. (2005). Motivasyon araçları ve iş tatmini: sosyal sigortalar kurumu başkanlığı hastane başhekim yardımcıları üzerinde bir araştırma. Sağlık İdaresi Dergisi, 8(3), 325-348.

Akbaba, S. (2006). Eğitimde Motivasyon. Kazım Karabekir Eğitim Fakültesi Dergisi, 13- 343-361.

Aydın, M. (2013). Eğitimde Örgütsel Davranış. Ankara: Gazi Kitabevi.

Aytürk, N. (2010). Örgütsel ve Yönetsel Davranış. Ankara: Detay Yayınclık.

Baymur, F. (1994). Genel Psikoloji. (11. Baskı). Ankara: Inkılap Kitabevi.

Byrne, B. M. (2010). Structural equation modeling with AMOS: Basic concepts, applications, and programming. New York: Routledge.

Byrnes, J. P. (2011) Academic Achievement. In B. B. Brown ve M. J. Prinstein (Eds.) Encyclopedia of Adolescence. Elsevier, San Diego: Acedemic Press.

Büyüköztürk,Ş. (2011). Sosyal Bilimler İçin Veri Analizi El Kitabı. (14. Baskı). Ankara: Pegem Akademi.

Coşkun, S. (2015). Kamu Hizmetleri Motivasyon Kuramı: Bir Literatür Taraması. Ekonomik ve Sosyal Araştrtmalar Dergisi, 11(1), 61-74. Cüceloğlu, D. (1996). İnsan ve Davranışı. (6. Baskı). i̇stanbul: Remzi Kitabevi.

Çokluk, Ö., Şekercioğlu, G. ve Büyüköztürk, Ş. (2012). Sosyal Bilimler İçin Çok Değişkenli istatistik SPSS ve LISREL Uygulamaları. (2. Baskı). Ankara: Pegem Akademi.

Deci, E. L., Ryan, R. M., ve Williams, G. C. (1996). Need Satisfaction and the Self-regulation of Learning. Learning and Individual Differences, 8, 165-183.

Demir, H. ve Okan, T. (2009). Motivasyon Üzerinde Ulusal Kültürün Etkisi. Gazi Üniversitesi Iktisadi ve İdari Bilimler Fakültesi Dergisi, 11(1), 121-142.

Erdem, A. R. (2015). Sınıfta Güdüleme, (Edit. Kıran, H. ve Çelik, K), Sınıf Yönetimi (11. Baskı). (203-223). Ankara: Anı Yayıncılık.

Eren, E. (2015). Örgütsel Davranış ve Yönetim Psikolojisi. (15. Baskı). İstanbul: Beta Basım Yayım Dağıtım.

Ersarı, G. ve Naktiyok, A. (2012). İşgörenlerin İçsel ve Dışsal Motivasyonunda Stresle Mücadele Tekniklerinin Rolü. Atatürk Üniversitesi Sosyal Bilimler Enstitüsü Dergisi,16(1), 81-101.

Fındıkçı, i. (2012). İnsan Kaynakları Yönetimi. (8. Baskı). İstanbul: Alfa Basım Yayım Dağııım.

Gürgan, U. (2016). Sınıfta Güdüleme. (6. Baskı). (Edit. Sarpkaya, R.). Sınıf Yönetimi. (295-326), Ankara: Maya Akademi.

Hitt, M. A., Miller, C. C. ve Colella, A. (2006). Organizational Behaviour: A Strategic Approach. Cheapter 6 Work Motivation, 195- 
232, Hoboken: John Willey Sons.

Hofstede, G. (1980). Culture's Consequences, International Differences in Work-Related Values. Sage Publication, London. Hoy, W. K. ve Miskel, C. G. (2010). Eğitim Yönetimi. (7. Baskı). (çev. Turan, S.). Ankara: Nobel Yayın Dağıtım.

$\mathrm{Hu}$, L.T. ve Bentler, P.M. (1998). Fit indices in covariance structure modeling: Sensitivity to under parameterized model misspecification. Psychological Methods, 3(4), 424-453.

Keser, A. (2005). Çalışma Yaşamı ile Yaşam Doyumu ilişkisine Teorik Bakış. İstanbul Üniversitesi İktisat Fakültesi Mecmuası, 55(1), 897-913.

Keleş, H. N. (2011). Y Kuşağı Çalışanlarının Motivasyon Profillerinin Belirlenmesine Yönelik Bir Araştırma. Organizasyon ve Yönetim Bilimleri, 3(2), 129-139.

Kline, Rex. B. (2005) Principles and Practice of Structural Equation Modeling. New York: The Guilford Press.

Koçel T. (2005). İşletme Yöneticiliği. İstanbul: Arıkan Yayıncılık.

Leonard, N, H., Beauvais, L. L. ve School, R. W. (1999). Work Motivation: The Incorporation of Self-Concept-Based Processes. Human Relations, 52(8), 969-974.

Lower, J. (2008). Brace Yourself Here Comes Generation Y. Critical Care Nurse, 28(5),80-84.

Mc Shane, S. L. ve Von Glinow, M. A. (2016). Örgütsel Davranış. (çev. Günsel, A. ve Bozkurt, S.) Ankara: Nobel Yayınları.

Mullins, L. J. (2006). Essentials of Organizational Behaviour. Work Motivation and Rewards (183-216). England: Prentice Hall.

Onay, M. ve Ergüden, S. (2011). Örgütsel-Yönetsel Motivasyon Faktörlerinin Çalışanların Performans ve Verimliliğine Etkilerini İncelemeye Yönelik Ampirik Bir Çalışma: Manisa-Sosyal Güvenlik Kurumu. Organizasyon ve Yönetim Bilimleri Dergisi, 3(2), 221-230.

Onur, B. (1997). Gelişim Psikolojisi. (4.Baskı). Ankara: İmge Kitabevi.

Öge, S. (2016). İnsan Kaynakları Yönetimi. (8. Baskı). Konya: Eğitim Yayınevi.

Ölçer, F. (2005). Departmanlı MAağazalarda Motivasyon Üzerine Bir Araşttrma. Erciyes Üniversitesi İktisadi ve İdari Bilimler Fakültesi Dergisi, 25,1-26.

Özkalp, E.ve Kırel, Ç. (2016). Örgütsel Davranış. (7. Baskı). Bursa: Ekin Yayınevi.

Öztürk, Z. (2013). Kamu Kurumlarında Motivasyon, Uzman Bakış Dergisi, 1 (1), 32-41. 28.12.2017 tarihinde http://www.mud.org. tr/uploads/yuklemeler/5_zekaiozturk.pdf adresinden erişilmiştir.

Ryan, R. M., ve Deci E. L. (2000 a). Intrinsic and Extrinsic Motivations: Classic Definitions and New Directions. Contemporary Educational Psychology, 25(1), 54-67.

Ryan, R. M., ve Deci, E. L. (2000 b); Self-Determination Theory and the Facilitation of Intrinsic Motivation, Social Development, and Well-being. American Psychologist, 55(1), 68-78.

Rigby, C. S., Deci, E. L., Patrick, B. C., ve Ryan, R. M. (1992). Beyond the Intrinsic-extrinsic Dichotomy: Self determination in Motivation and Learning. Motivation and Emotion, 16, 165-185.

Sabuncuoğlu, Z. ve Tüz, M. (1998). Örgütsel Psikoloji. (3. Baskı). Bursa: Alfa Aktüel Yayınları.

Sabuncuoğlu, Z., ve Vergiliel Tüz, M. (2013). Örgütsel Davranış, Bursa: Alfa Aktüel Yayınları.

Sağır, M. (2016). Sınıfta Motivasyon Süreci. (3. Baskı). (Edit. Argon, T. ve Sezgin Nartgün, Ş.). Sınıf Yönetimi. (121-137). Ankara: Maya Akademi.

Seçer, i. (2015). Psikolojik Test Geliştirme ve Uyarlama Süreci. Ankara: Anı Yayıncılık.

Şeker, S. E. (2015). Motivasyon Teorisi. YBS Ansiklopedi, 2(1), 23 - 27.

Şencan, H. (2005). Sosyal ve Davranışsal Ölçümlerde Güvenilirlik ve Geçerlilik. Ankara: Seçkin Yayıncılık.

Toker, B. (2006). Konaklama İşletmelerinde İşgören Motivasyonu ve Motivasyonun İş Doyumuna Etkileri - İzmir'deki Beş ve Dört Yıldızlı Otellere Yönelik Bir Uygulama. Yayınlanmamış Doktora Tezi. Dokuz Eylül Üniversitesi Sosyal Bilimler Enstitüsü, İzmir.

Tulunay Ateş, Ö. ve Buluç, B. (2015). The Relationship between the Emotional Intelligence, Motivation and Organizational Commitment of Primary School Teachers. Middle Eastern African Journal of Educational Research, 17, 31-49.

Uğurlu, C. T. (2016). Sınıf Yönetimi, Ankara: Anı Yayıncılık.

Yavuz, C. ve Karadeniz, B. C. (2009). Sınıf öğretmenlerinin motivasyonunun iş tatmini üzerine etkisi, Uluslararası Sosyal Araştırmalar Dergisi, 2(9), 507-519.

Yücel, C. ve Gülveren, H. (2016). Sınıfta Öğrencilerin Motivasyonu. (13. Baskı). Edit. Şişman, M. ve Turan, S.). Sınıf Yönetimi. Ankara: Pegem Akademi. 